\title{
EMOTIONS IN HEIDEGGER AND SARTRE
}

\section{ANTHONY HATZIMOYSIS}

\subsection{Emotions in Phenomenology}

Phenomenology has done more than any other school of thought for bringing emotions to the forefront of philosophical inquiry. The main reason for the interest shown by phenomenologists in the nature of emotions is perhaps not easily discernible. It might be thought that phenomenologists focus on emotions because the felt $\square$ quality of most emotional states renders them a privileged object of inquiry into the phenomenal properties of human experience. That view, in its turn, might lead one to think that phenomenologists attend to emotional experience for its highly subjective character. On the contrary, it is the ability of emotions to engage with reality that makes them crucial for phenomenological analysis. Emotional experience is an opening to the salient features of a situation; undergoing an emotion is a way - and, for some phenomenologists, the principal way in which the world manifests itself to us. The exact character of that manifestation will be the main topic of discussion in the present chapter.

We shall look at the two major accounts of the way in which that manifestation is structured. The first account is due to Martin Heidegger, and the second is articulated in the writings of Jean-Paul Sartre. The choice of focus on Heidegger and Sartre is guided by several considerations. They treat emotion as a distinct 
topic of philosophical research rather than as a side-issue upon which a readymade theory of mind is to be applied. They are both primarily interested in the nature of emotion in general rather than in the particularities of a few cases. They both formulate important challenges to the picture of emotions as 'blind' or 'ineffable feelings', closed within themselves. Finally, it is those two phenomenologists who have attracted most interest in recent years - and for good reason since it is in their work that we find not only perceptive answers to some classic questions but also a new way of approaching emotional phenomena.

The theories articulated by Heidegger and Sartre build upon a view of emotional states variously defended by Brentano, Husserl, and Scheler, and further developed by Merleau-Ponty, Levinas, and Ricoeur. Among the several representatives of that tradition in the English-speaking world, one should not fail to mention Robert Solomon, whose rich and insightful work in that area was crucial in bringing phenomenological theories to the attention of contemporary philosophers of emotion.

In the next section I identify some of the difficulties in making proper sense of Heidegger's approach to affective phenomena. Then I offer a reading, which, in my opinion, saves most of the textual phenomena, while bringing to the fore the significance of Heidegger's account not just for the analysis of emotion but for the philosophical conception of self-awareness as a whole. In section 9.3 I introduce Sartre's view of affectivity, and in sections 9.4 and 9.5 I reconstruct his phenomenologically rich account of emotional activity.

The choice of presentation for the work of two major philosophers poses its own methodological concerns. Some scholars might have opted for an overview of their system; my presentation, on the other hand, is based on a rather close reading of specific paragraphs. We shall focus on parts of the philosophical texts that have rightly exerted considerable influence in analytic discussions over the nature of emotional phenomena.

\subsection{Reading Heidegger on emotion:}

\section{SOME DIFFICULTIES}

Heidegger's writings share with some classic texts of German philosophy the curious fate of being judged very influential, yet highly obscure. Among the influential points attributed to his work we should include the claims that: (i) in affective experience we are somehow attuned to the world; (ii) moods are, in some sense, prior to emotions; (iii) we are always in some mood; and (iv) there is a small 
set of fundamental moods, attendance to which reveals important truths about human existence.

Those claims purport to summarize the theory of emotion put forward in Being and Time. In the central sections of that work Heidegger presents an account which brings together points pursued in some of his earlier work and which is elaborated upon, without major changes, in most of his subsequent writings. ${ }^{1}$ Yet, a careful reading of those three sections appears to generate more questions than answers. I would like to take the standpoint of someone who comes to that text for the first time, and, equipped with some basic understanding of current work on emotions, wishes to make sense of what they read, especially in the crucial §29, of Heidegger's magnus opus.

The common modern German terms for emotion, i.e., Gefühl and Affekt, are used by Heidegger sparingly, and mainly in the course of clarifying his attitude towards the views of his philosophical predecessors. Instead, in Being and Time we read mostly about Stimmung, a term often translated as 'mood'. It might be thought that this is not a real issue; it simply indicates that, when it comes to the details of his account, Heidegger's concern is not with emotion proper but with moods. However, this reasonable suggestion does not offer an easy way out of our interpretative difficulties. Consider, for a start, the fact that when Heidegger attempts to illustrate his view of moods, he discusses fear, which has always been taken as a paradigmatic case of emotion. It would not help either to think that, for Heidegger, the traditional taxonomy of affective states has got it wrong, and that fear is a mood and not an emotion, since Heidegger attributes to fear precisely those characteristics (specificity of intentional target, limited duration of relevant experience, explicit concern about our well-being in view of an identifiable threat), which mark fear not as a mood but as an emotion.

We may see our way through this issue by examining a term Heidegger devises for referring to the relevant phenomena: Befindlichkeit. ${ }^{2}$ Derived from the reflexive verb sich befinden, which in the present context means 'to find oneself' (in a place, or a situation), Befindlichkeit can at a first approximation be translated by the phrase 'that one is found' (in a place, or a situation). ${ }^{3}$ We might thus be helped in our reading by considering both moods and emotions as exemplifications of the

1 Of particular importance are Sections 28, 29, 30, and 40. Heidegger's account of emotion is clarified or partly elaborated in subsequent writings, without, in my view, undergoing any major changes. Some of the new claims Heidegger brings into his discussion concern mainly his original and insightful interpretation of other philosophers' views, especially those of Plato and Nietzsche; cf. his remarks in Was ist das-die Philosophie? (Pfullingen: Günther Neske, 1956) and in Nietzsche: Der Wille zur Macht als Kunst (Frankfurt a.M.: Klostermann, 1984), pp. 53-9.

2 'Fear', as Heidegger often repeats, 'is a mode of Befindlichkeit'. See Being and Time (Oxford: Blackwell, 1962), a translation by John Macquarrie and Edward Robinson of Sein und Zeit (Tübingen: Max Niemeyer Verlag) - henceforth cited as SZ - pp. 134, 140.

3 The passive grammatical construction is intended to convey the sense of being thrown into being in a place or a situation, a phenomenon aptly expressed by Heidegger's notion of Geworfenheit. 
overarching phenomenon of finding ourselves in some situation. This interpretation sounds more plausible if we connect Heidegger's technical noun with the colloquial phrase 'Wie befinden Sie sich?', which can be translated as 'How do you find yourself?', or more naturally as 'How do you feel?', while an answer to that question expresses 'wie einem ist und wird', 'how one is [or feels], and how one becomes [to be or to feel]' ${ }^{4}$

However, the fusing together of the meanings implicit in colloquial phrases might make us suspect that what we are offered is not a secure bridging of, but a quick glossing over the difference between 'how one is' and 'how one feels that one is'. We may attempt to connect the two by invoking a psychological process that links one's cognition or, at least, one's perception of 'how one is' to the arising of a feeling about that which is cognized or perceived.

Going down that route, however, will take us even further away from Heidegger's programme. On the one hand, the appeal to such a psychological process is at odds with Heidegger's statement that Befindlichkeit is precisely not just another psychological state - next to cognition, presentation, or volition - a state to be added or subtracted from our mental economy; indeed, his ardent critique of the mindworld dichotomy entails that, for Heidegger, Befindlichkeit is anything but a 'state of mind'.

On the other hand, neither Befindlichkeit nor Stimmung should be thought of as picking out something that arises after cognitive or perceptual awareness: the 'affective' is either fully fused (and, thus, simultaneous) with the cognitive and the perceptual, or arises prior to them. ${ }^{5}$ Heidegger expresses the former point by asserting that the 'affective' is involved in our perceptual and cognitive engagement with the world, present in even our most abstract intellectual endeavours: 'even the purest theory has not left all Stimmungen behind it' ( $S Z$ 138). Heidegger's point, though, is not identical to a similar-sounding claim, popular both within and outside phenomenological circles, that the awareness of an object brings with it an affective quality. His claim is not that, in seeing or intuiting something, we (simultaneously) experience certain feelings or passions. Rather, his view is that unless we approach a thing with a certain Stimmung, that thing will not reveal itself to us as it really is. ${ }^{6}$ That is certainly an important claim, but some care is needed in how we interpret its role in the present context. Heidegger is not arguing for that

$4 S Z$ 134: 'wie einem ist und wird': literally, 'how it is and becomes for one.'

5 I place the 'affective' in quotes because it has not been specified, yet, in what sense Befindlichkeit and Stimmung should count as affective phenomena.

6 A point that applies equally to our scientific and philosophical inquiries, as noted by Aristotle in Book A of his Metaphysics, and quoted approvingly by Heidegger: '[the thing will] not show itself purely as it looks unless the theoretical look lets it come towards us in a tranquil tarrying alongside..., in comfort and recreation' ( $S Z_{138}$ ). The terms in italics are given in Greek in Heidegger's free rendering of Aristotle's text: they are all taken from Met A2, 982b 22. 
claim, but from it: he simply asserts that this is how things are, invoking Aristotle's authority in its support.

It might be retorted that Heidegger does not need to argue for a claim that merely describes the affective dimension of intellectual activity. After all, what sort of phenomenologist would Heidegger be (the retort goes), if he did not take ordinary experience at face value? The problem is that, at other parts of that text, Heidegger appears to do anything but accept the verdict of the 'average everyday understanding' of the relevant phenomena. In the second paragraph of $\$ 29$, for instance, he lists a number of possible counterexamples to his thesis that one is always already in a mood [ist gestimmt], but he then promptly dismisses them: 'the undisturbed equanimity', as well as 'the pallid, evenly balanced lack of mood [Ungestimmtheit]' are in fact... moods $(S Z$ 134). A different approach to Heidegger's text is needed, if we are to save it from apparent inconsistencies of this kind.

Note that these difficulties will not go away just by replacing the standard translation of Stimmung as 'mood' with that of 'attunement'. The etymological analysis of the word indicates that Stimmung can mean the tuning of an instrument. It may thus be reasonably suggested that the previous objections to Heidegger's account of Stimmung miss their mark, given that what Heidegger is proposing is not an account of moods, but of the very different phenomenon of somehow 'being attuned to' the world in general, or with the particular situation in which one is found. That reading is certainly closer to the spirit of Heidegger's approach. However, it cannot, by itself, resolve some of the interpretative difficulties already encountered, while it gives rise to some new ones. The above-mentioned, apparent inconsistency remains: what the phenomenology of ordinary experience presents as being ungestimmt ['being out of tune', according to the new translation] is, according to Heidegger, a case of Gestimmtsein ['being attuned']. Secondly, the claim about the alleged fusion of Stimmung with every instance of cognitive or perceptual awareness increases in plausibility, but also loses a lot of its significance. What Heidegger seems to be saying is that someone cannot see some thing as it is, and for what it is (or, to use the phenomenologically correct turn of phrase: someone cannot let some thing manifest itself to them, as it is and for what it is), unless someone is somehow attuned to that thing. That claim sounds correct (at least to my philosophical ear), but the worry is that part of its appeal is that it is a claim so vague that one might appear foolish to deny it. That vagueness is I think due to two reasons. First, the claim is not argued for but is blandly asserted (invoking, as already mentioned, Aristotle's authority). Secondly, it is not explicated how or why the so-called 'attunement' relates to the topic of our discussion: the nature of emotional phenomena. The expression 'being attuned to' (the world etc.) does not on its own indicate how it bears upon anything that might fall under the heading of affect. At the very least, the attempted connection between attunement and emotion leaves open four very different options: (i) emotion and attunement are two independent occurrences, but the presence of the former 
facilitates the success of the latter; (ii) emotion is dependent on attunement in the sense that one is not able to experience an emotion about anything unless one is attuned to that thing [where: 'attuned to' is not emotionally loaded, on pain of circularity]; (iii) being attuned is dependent on emotion, in the sense that unless one is emotionally engaged with some thing, one cannot 'tune oneself to' that thing [whatever that 'tuning oneself to' might mean]; (iv) 'emotion' and 'attunement' denote exactly the same occurrence: what Heidegger's analysis aims to show is that what traditionally goes under the name of 'emotion' is really the attunement of oneself to the world.

The last point is of course the most interesting. Unfortunately, though, in the absence of a proper cashing out of the 'attunement' metaphor, it is also the hardest to defend. In the next section we shall tread a different path through the Heideggerian maze with the hope of reaching a better understanding of Befindlichkeit, as well a clearer view of the motivation for the attempted identification of Stimmungen with emotions.

\subsection{Heidegger on EMOTIONAL aWARENESS}

\section{OF BEING IN THE WORLD}

As you might have noticed, our presentation has not yet employed Heidegger's most famous term: Dasein. Let us see how a basic grasp of that notion might relieve some of the interpretative difficulties identified in the previous section.

Dasein is translated as 'being-there', but Dasein's 'there' is inclusive of, not contrasted to, its 'here'. The prefix $D a$ points both to a 'here' [Hier] and to a 'yonder' [Dort] ( $S Z$ 132). Depending on the analytical context, Heidegger switches emphasis from the 'yonder' to the 'here', while constantly reminding us that Dasein is not a thing for which 'here' and 'yonder' refer to two independently existing points in absolute space but a totality whose 'here' and 'yonder' are two intrinsically related aspects, given Dasein's way of existing as directed towards 'ready-tohand things', which are encountered 'within-the-world', and with which Dasein is constantly engaged. ${ }^{7}$

Heidegger proceeds from these basic observations to make a twofold claim, a claim that, in Heidegger's characteristic manner, is both transcendental and phenomenological. As a transcendental claim, it states the condition for the possibility of something - in this case, the possibility of 'here' and 'yonder'. As a

7 This basic analysis applies to the relation of 'concern' characteristic of 'being alongside the world'; 'solicitude' has a different structure in so far as it denotes Dasein's relation to being-with (others). 
phenomenological claim, it identifies that condition with a phenomenon, i.e., with something that 'shows-itself-in-itself' ( $\left.S Z_{31}\right)$. Heidegger's claim is that 'here' and 'yonder' are possible because there is a being whose way of existing discloses simultaneously the 'being-yonder' of the world, and the 'being-here' of itself. That being has to be an entity whose way of being is necessarily that of 'beingthere'. And that, of course, is Dasein: the being whose essence is that of being-inthe-world. ${ }^{8}$

The question now arises as to what exactly that 'being-in' consists in. It would be misleading, according to Heidegger, to present the 'being-in' as what may come in 'between', and thus conjoin, two self-subsistent entities; or even to think of it as the contingent agreement of, for example, an immaterial subject, and a material object. It would be no less false to conceive of 'being-in' as the extant relationship of two differently sized present-at-hand things, e.g. of a smaller box being-inside a bigger box. But if Dasein's 'being-in' the world is neither a 'between' [Zwischen], nor an agreement [convenientia], nor insideness [Inwedigkeit], what is it? The brief answer is: Befindlichkeit. Or, more precisely, 'being-in-the-world' is Dasein's mode of existing, as that mode is disclosed in the phenomenon of Befindlichkeit.

The importance of Befindlichkeit for the ontology of Dasein is hard to miss. What is less evident, though, is why anyone would think that that notion is relevant to a philosophical inquiry into human emotions. Part of the explanation, I think, is found in the origins of that notion in Heidegger's reading of a classic text in emotion theory. In the summer of 1924, Heidegger gave a series of lectures on Aristotle's philosophy, addressing the pioneering view of emotions expounded in the Second Book of Rhetoric. The Aristotelian analysis pays special attention to how

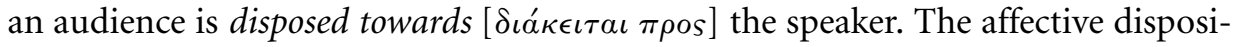
tion [ $\left.\delta \iota^{\prime} \theta \epsilon \sigma \iota s\right]$ is one of the senses of 'Stimmung', when that word is used to highlight one's tendency or readiness to engage with something or someone emotionally, not unlike the English term 'mood' employed with a subjunctive object, e.g., 'I am in the mood for love' (as the song would have it). That dimension of one's affective engagement with beings encountered within the world, in general, is underplayed in the Aristotle Lectures but is brought to the fore in Being and Time. However, what is really significant for our inquiry is that when Heidegger discusses the famous paragraphs on the passions [ $\pi \alpha \dot{\theta} \theta \eta$, Affekte] experienced by the audience in attending to the orator's speech, Heidegger's term of choice for rendering both $\pi \alpha \dot{\theta} \eta \eta$ and $\delta \iota \alpha \theta^{\prime} \sigma \epsilon \iota s$ is Befindlichkeit. ${ }^{9}$

We have so far seen, very briefly, some of the ontological grounds for bringing Befindlichkeit into the analysis of Dasein, as well as some philological evidence for

8 'The entity which is essentially constituted by being-in-the-world is itself in every case its there' $\left(S Z{ }_{132}\right)$.

9 Grundbegriffe der aritotelischen Philosophie, Gesamtausgabe, vol. 18, edited by M. Michalski. Frankfurt a.M.: Klostermann, 2002; see especially the discussion on pages 176-7. 
Heidegger's penchant for that notion when he discusses affective phenomena. But are there any good grounds for connecting the two? Why would a notion expressive of affective experiences be the key to the ontological puzzle over the awareness of being-in-the-world? Let me reconstruct part of the Heideggerian response to our query.

Heidegger's inquiry is a search for the meaning of being. He wants to understand how being itself can be revealed, outside the conceptual strictures of scholastic metaphysics. Among the various notions he employs for characterizing Dasein's coming to the truth of being, it is 'disclosure' [Erschlossenheit] that he seems to reserve for the bringing to light of the being of the world itself, as distinguished from the appearing of inworldly entities, which 'manifest themselves' or 'showthemselves-in-themselves.' ${ }^{10}$ More precisely, Heidegger is at pains to identify a phenomenon of disclosure which meets the following desiderata: (i) it discloses the Da of Dasein, the fact of its being-in-the world; (ii) it discloses entities encountered within-the-world; (iii) (i) and (ii) are achieved simultaneously, in equal measure, and with no metaphysical priority, i.e., 'equiprimordially'; (iv) the disclosure is not deliberately brought about, it is not the outcome of voluntarily effort, but it is something that 'befalls' Dasein; (v) it is a disclosure that should be sharply contrasted with any kind of cognition or observation, including 'theoretical intuition', 'perceptual understanding, 'beholding, 'looking at', 'staring', 'reflecting', 'cognizing', and 'knowing.' 1

According to Heidegger, the awareness enabled by affective experience meets all of the above desiderata. Consider the main example he presents for illustrating his case: ' . . fearing about something, as being afraid in the face of something, always discloses equiprimordially entities within-the-world and being-in - the former as threatening and the latter as threatened. Fear is a mode of Befindlichkeit' ( $S Z_{141}$ ).

As that quotation makes clear, fearing meets conditions (i), (ii), and (iii). It also meets condition (iv) in the sense that one does not, normally, exert special effort to become afraid of something one does not consider fearful: the emotion 'befalls', 'comes' or 'arises into' one, when one encounters the fearful. Not all emotions follow the same pattern of arousal. Yet, none, according to Heidegger, make us aware of things in the world through a two-step programme of first cognizing a neutral entity, and then (voluntary, deliberately, or otherwise) projecting onto it a

10 (SZ 132) 'Unhidness', 'Uncoveredness', and 'Openness' are some of the notions Heidegger uses in discussing being's self-revelation. With a direct allusion to a traditional philosophical metaphor, Heidegger invokes yet another term, Lichtung, to illustrate how Dasein itself "is "illuminated" [erleuchtet], meaning: lightened [gelichtet] in itself as being-in-the-world, not by another entity but in being itself the lightening' ( $S Z_{133}$ ). In what follows, for the sake of brevity, I reconstruct Heidegger's reasoning employing only the core term 'disclosure', instead of the variety of similar (though, by no means identical) technical terms.

11 Sections 28, 29, and 30 abound with Heidegger's warnings against the confusion of Befindlichkeit or Stimmungen with any kind of cognitive or perceptual awareness, but see especially $S Z$ 134, 136 . 
psychical colouring. In fearing, for example, 'we do not first ascertain a future evil and then fear it. But neither does fearing first take notice of what is drawing close; it discovers it beforehand in its fearsomeness' ( $S Z$ 141).

And so we reach what in my view is the most crucial condition: that the disclosure effected in emotional experience is not of a cognitive or observational nature. Here we need to distinguish among different levels of analysis. The obvious way of interpreting the claim that condition ( $\mathrm{v}$ ) is met by emotional experience is to contend that, as a matter of phenomenological fact, emotions disclose in a noncognitive, non-observational manner. That contention can be further substantiated by the ontological claim that, in emotional experience, ourselves and the world are disclosed in a way that precedes and grounds any perceptual, theoretical, reflective, or cognitive grasp of both the 'here' of ourself and the 'yonder' of the world ( $S Z$ 134-6). 'Fearing', for instance, 'as a slumbering possibility of the affectively found [befindlichen] being-in-the-world, ... has already disclosed the world, in that out of it something like the fearsome may come close [to us]' ( $S Z_{141}$, tr. changed).

However, Heidegger's extant discussion of those issues seems to create a serious problem that appears to slip easily under the scholarly radar. Let me explicate what the problem is by focusing on the 'here' side of emotional disclosure.

For Heidegger's argumentation to work, his claim should be not only that the emotional awareness of ourself is non-cognitive, pre-reflective, or non-observational but also that the non-cognitive, the pre-reflective, non-observational awareness of ourself is emotional. Heidegger makes a case (in my view, a very strong case) for the claim that emotions disclose Dasein to itself as being-in-the-world, in a pre-reflective etc. manner. To identify, though, Dasein's pre-reflective etc. disclosure with emotional experience, we need a case to be made for the claim that Dasein cannot pre-reflectively etc. be disclosed to itself, unless it is in some emotional mode. And that is something for which Heidegger's text does not seem to provide adequately.

It is worth revisiting, at this point, an issue we touched upon at the beginning of our presentation. Section 29 opens with a declaration of the ever-present Stimmungen in our life. Heidegger maintains that apparent counterexamples to his thesis should be dismissed. We can now see why Heidegger is adamant on this issue: dispensing with Stimmung would amount to no less than losing our primordial (non-observational, pre-reflective, first-person) awareness of our own self. The stakes on this issue are sufficiently high for Heidegger to momentarily slip into a less than perfect attention to terminological detail. Recall that a counterexample to his approach is that there is such a thing as 'pallid, evenly balanced lack of mood [Ungestimmtheit], which is ... not to be mistaken for a bad mood [Verstimmung], is far from nothing at all. Rather' - the standard English translation continues - 'it is in this that Dasein becomes satiated with itself. Being has become manifest as a burden' ( $S Z_{134}$ ). The translation makes it sound as if it is the 'lack of mood' which is revealing of the being as a burden. The original, though, clarifies that it is 'bad 
mood' that offers that manifestation: 'Das Sein des Da ist in solcher Verstimmung [not: Ungestimmung] als Last offenbar werden'. ${ }^{12}$

Perhaps one should not dwell on such terminological issues. What matters is that Heidegger's illuminating discussion of the disclosive capacity of emotional experience in all its varied forms does not as such preclude the availability of being attuned to oneself and to the world in an emotion-free mode.

The belief in the availability of a pre-reflective, non-observational, yet emotionfree first-person awareness of oneself as being (located) in the world is by no means antithetical to a phenomenological inquiry. After all, it is what Husserl argued for, in exhaustive detail. It is also the view of a phenomenologist who, despite his stated admiration for Heidegger, presents a methodologically more conservative, or, at least, less ambitious theory of emotional awareness. Sartre did not dig as deep as Heidegger into the foundations of being; neither did he grapple with some borderline cases of emotional experience, with the intellectual fortitude that characterizes Heidegger's discussion of one's awareness of one's own being and non-being. Yet, Sartre offers something that was to prove crucial in all subsequent discussions of emotion: that 'action' is no less an important aspect of emotional phenomena than 'passion'.

\subsection{Sartre on EMOTIONAL CONSCIOUSNESS}

Emotions make their appearance in every single philosophical text written by Sartre. Beginning with his seminal paper on Intentionality, ${ }^{13}$ and moving through his pioneering study of the Ego, ${ }^{14}$ the treatises on Imagination, ${ }^{15}$ and his magnus opus in the ontology of our concrete relations with others, ${ }^{16}$ through his rich observations in the posthumously published Notebooks on Ethics, ${ }^{17}$ and concluding

12 Literally: 'The being of there becomes manifest as a burden in such bad mood.'

13 'Intentionality: A Fundamental idea in Husserl's Phenomenology' Journal of the British Society of Phenomenology, 1, No. 2 (1970): 4-5, a translation by Joseph Fell of 'Une Idée fondamentale de la phénoménologie de Husserl: l'intentionnalité', in Situations I (Paris; Gallimard, 1947), pp. 31-4.

14 The Transcendence of the Ego (London: Routledge: 2004), a translation by Andrew Brown of La Transcendance de l'Ego (Paris: Librairie Philosophique, 1988) - first published in Recherches Philosophiques (1937).

15 L'Imagination (Paris: Presses Universitaires de France, 1936) and esp. Parts III and IV of The Imaginary: A Phenomenological Psychology of the Imagination (London: Routledge, 2004), a translation by Jonathan Webber of L'Imaginaire: psychologie phénoménologique de l'imagination (Paris: Gallimard, 1940).

16 Being and Nothingness (Oxon: Routledge Classics, 2003), a translation by Hazel Barnes of L'Être et le néant: Essai d’ontologie phénoménologique (Paris: Gallimard, 1943); see Part III, 3.

17 Cahiers pour une morale (Paris: Gallimard, 1983). 
with his voluminous biography of Flaubert, ${ }^{18}$ Sartre observed with an unflinching eye the moving generosity and the common duplicity, the existential revelations and the mundane self-deceptions, all the highs and the lows of our emotional involvement with each other. His most famous book, after all, illuminates the epistemic, normative, and ontological aspects of a unique affective experience: nausea. It is not on that novel, however, that we shall focus here but on a short, and tightly argued, treatise published in the same year. ${ }^{19}$ The Sketch presents a detailed critique of subjectivist feeling-based theories, and challenges some reductionist versions of cognitivist and psychoanalytic models of emotion. ${ }^{20}$ The book's influence, though, lies not in its critical agenda but in its positive programme, which often, in the secondary literature, gets summarized with the catch phrase 'emotions are actions'. We shall see that this way of presenting the Sartrean view is inaccurate, since - selective readings to the contrary - Sartre actually denies that emotions are actions. The analysis of these issues requires a clear grasp of the Sartrean conception of psychological states. I shall accordingly begin with a brief account of the Sartrean view of those states. I will then present Sartre's views on the relation between emotional awareness and behavioural reaction, and shall conclude with his interpretation of action out of emotion. Our discussion will be informed by the Sartrean idea that the philosophical analysis of emotions should inquire about what an emotion signifies: what it indicates for the life of the person that experiences the emotion, and which aspect of reality is indicated when the person is emotionally directed towards the world.

Sartre maintains that affective states, such as boredom, jealousy, or hatred, appear as psychical objects when we reflect on our past mental or physical activities. Take for instance the relation between the feeling of revulsion and the state of hatred. Feeling revulsion at the sight of a particular person is an experience absorbed with the detestable qualities of that individual. Experienced as a direct engagement with the world, the upheaval of a particular feeling towards someone marks the intentional connection between my consciousness and that being. The feeling of revulsion is a conscious activity occurring instantaneously or through a limited time span, and one that meets Sartre's absolute principle of consciousness, i.e., to be an instant of revulsion and to feel as an instant of revulsion are one and the same thing: there is no gap within the 'consciousness (of) revulsion' between appearing and being. ${ }^{21}$

The genitive construction 'consciousness of revulsion' might give the impression that, in the course of ordinary encounter with the world, there is a thing called

18 L'Idiot de la famille. Gustave Flaubert de 1821 à 1857, t. I-III (Paris: Gallimard, 1971-72).

191938 sees the publication of both Sartre's 'sketch' on emotion, in the series Actualités Scientifiques Industrielles, and of his first novel with Librairie Gallimard.

20 Sketch for a Theory of the Emotions (London: Routledge Classics, 2004) - henceforth cited as STEa translation by Philip Mariet of Esquisse d'une théorie des emotions (Paris: Hermann).

21 Cf. Transcendence of the Ego, pp. 22-3. 
'revulsion' to which consciousness pays attention. That view is false. Revulsion is not an object for consciousness; it is consciousness itself as it experiences its intentional object. The genitive participle 'of' is put in brackets so as to signal that the grammatical construction purports to characterize what a particular consciousness is (namely, revulsion), not what the consciousness is about (its intentional object, the particular person who just started addressing a political rally). Similarly, the locution 'consciousness (of) despair' denotes, in the present context, a 'despairing consciousness' - how an agent experiences a world where all possibilities are barred - not that his experience is about a certain object called 'despair'.

However, if we were to move from the plane of emotional encounter with the world to the higher level of reflection upon that type of encounter, our consciousness could take in its purview the emotion-consciousness. At that level, revulsion or other emotional experiences would themselves become an object of conscious examination and, thus, the locution 'consciousness of revulsion' (free of internal brackets) would denote the second-order activity of consciousness focusing upon its conscious activities. The confusion of the first-order level of the (revulsive, despairing, or joyous) experience of the world, with the second-order level of the consideration of such an experience by the (reflective) subject is a major source of difficulties for the adequate analysis of emotional phenomena.

The confusion of levels is itself the outcome of two kinds of pressure. The first stems from the unobjectionable claim that people are aware of having various emotions. That claim is taken to entail that what people are conscious of during an emotional episode is their own feelings. However, the latter claim is much stronger than, and it does not on its own follow upon, the former claim. To effect the transition one should draw on the dubitable principle that one cannot be aware of $\mathrm{x}$, unless $\mathrm{x}$ is the explicit object of conscious attention. Sartre repudiates this view on two grounds. On the one hand, it falls foul of the phenomenology of conscious experience. On the other hand, it entangles consciousness in an infinite recurrence of reflective acts on pain of rendering conscious experience unconscious. The issues raised by the last contention cannot be taken up here. ${ }^{22}$ Suffice it to note that consciousness' (non-reflective) awareness of itself need not be cast in conceptual terms. Hence, it is not a consequence of the Sartrean approach that, to be aware of feeling a particular way towards someone, one should conceive of his feeling under a particular heading. All that the present view implies is that for an experience to be conscious it need not take itself as its intentional object. For Sartre, a particular experience of revulsion is simply a conscious experience that is appropriately focused on a detestable person, that is, on something other than the experience itself.

22 Cf. Being and Nothingness, 'Introduction' and Part I ch. 1, as well as Transcendence of the Ego, Part A. 
However, the alleged importance of reflective activity is apparent not only in the context of theoretical debates but also in the way that we usually think and talk about emotional phenomena. In ordinary discourse about psychological phenomena, emotional states are marked by a fixity and duration that transcends the fleeting nature of emotional feelings. The state of hatred may extend well beyond the instantaneous encounter with the repulsive person, as it underpins past feelings of disgust, aversion, or anger towards him over a period of days, weeks, or even years. It is thus thought to continue to exist even when I am absorbed in different activities, and to make its appearance each time it finds an expression at the prompting of events that present me with the detestable person. Hatred is not exhausted by a particular episode of feeling revulsion: the state was here yesterday when the feeling was not, and it might be here tomorrow well after my feeling has ceased to exist. To move from the claim 'I am feeling revulsion while looking at him' to the claim 'I hate him' is to perform a 'passage to infinity': to state that you hate someone is, in essence, to give your verdict on what your feelings towards him meant in the past and to express a commitment as to how you are to think, feel, or act towards that person in the future.

According to Sartre, any 'psychic state' - including 'emotional states' such as hate - does not denote a fixed entity awaiting to be discovered but the product of our attempt to make sense of our experience, by setting our mental and physical activities into some intelligible order. At the ordinary, pre-reflective stage one is absorbed in things one encounters, or in the tasks at hand; there is feeling, seeing, thinking, or acting, but no psychic state that allegedly precedes and causes any of those activities or experiences; the psychic state appears when a reflective consciousness turns its attention on past conscious activities and purviews those consciousnesses under the heading of a particular concept.

According to Sartre, the state is a relative being, depending for its existence on the reflective gaze upon the ordinary conscious experience of things or events in the world. However, in a reversal of actual priorities, the reflectively created state is taken to underlie one's feelings, thoughts, and actions. The state appears as the principle that ties together various activities of consciousness, and holds the meaning of one's relation to the world. The analysis of that relation thus becomes an exploration of the allegedly hidden meaning of conscious experience. Our feelings, thoughts, and actions provide clues to the mechanics of each psychic state that acts upon the agent as a physical force, accounting for their past attitude and conditioning their future stance. Hence, the aim of the scientist of psychic states is to try to uncover the meaning of the state through the psycho-analysis of verbal and physical behaviour, viewed as the external mantle of inner psychic entities. On this point, some trends in contemporary cognitive psychology and in classical psychoanalysis concur in their view of emotional states as entities to which the agent can have only restricted access, and over which he or she may enjoy very limited control. The vocabulary of passivity that permeates much of the folk 
and scientific discourse on emotions reflects a conception of human beings as governed by entities dwelling somewhere between the spontaneous activities of the stream of consciousness, on the one hand, and the bodily constitution of our interaction with the world, on the other. The space in between the mental and the physical is that of the psychological, whose dual character speaks to the paradoxical nature of emotional states: passive yet purposive, involuntary but intentional, evaluative no less than physiological.

The occurrence of paradox might be a warning against setting psychic states as the starting point of a philosophical inquiry into emotional phenomena. However, that is not the main objection that Sartre reserves for the standard view of emotions. The real problem, for Sartre, is that zooming in on psychic states produces theoretical short-sightedness: psychic states cannot be studied independently of human nature and the world in general since the psychic facts that we meet in our research are never prior: 'they, in their essential structure, are reactions of man to the world: they therefore presuppose man and the world, and cannot take on their true meaning unless those two notions have first been elucidated' (STE 7-8).

\subsection{SARTRE AND THE BEHAVIOURIST APPROACH TO EMOTION}

Among the various aspects of emotion examined by Sartre, the behavioural manifestations of emotional experience are of particular importance for him. The initial attraction of a behaviourist approach to emotion is that, in contradistinction to traditional subjectivist accounts, it is an approach that leaves the private chambers of bodily sensations for the public space of human interaction. Behaviourism purports to analyse emotion in terms of the behaviour exhibited by a subject in the grip of an emotion (STE 17-26). We may identify three features of that theory that appeal to Sartre: it is a theory that views emotion as an integral part of a subject's interaction with his or her environment, it purports to highlight aspects of emotional phenomena that are amenable to objective description, and it offers a method of understanding the occurrence of emotional reactions that might otherwise appear unnecessary or counterproductive (STE 18). I will reconstruct the analysis of emotional behaviour offered by the present model before I address some methodological questions about the Sartrean critique, and eventual rejection, of behaviourism.

A subject encounters a situation that calls for a certain type of action, A1. What makes the performance of $A_{1}$ the appropriate type of response is determined by the 
goal the subject is to achieve, in the light of his or her particular role, as this is set by the implicit or explicit (cultural, social, family, etc.) rules that - ought to - govern his or her behaviour in the relevant context. However, in some circumstances, the cost of performing $\mathrm{A}_{1}$ is too dear for the subject to incur. He or she therefore opts for a different response, A2, whose enactment transforms the shape of the situation in a way that the subject is released from the obligation of performing A1. Because A2 falls short of achieving the declared goal, it signals a kind of failure or 'defeat' on the part of the subject. That behaviour of defeat is the emotion (STE 19).

The above paragraph outlines the sequence of events that, according to the theory examined by Sartre, constitutes an emotional episode. However, what makes that theory of emotion behaviourist is not its analysis of emotion in the terms of that sequence but the particular way that sequence is interpreted. The behaviourist understands that sequence as a continuous process that leads seamlessly from the presentation of a demand to the subject, to the subject's responding in a sub-optimal fashion. The mechanics of that response is a focal point of discussion within the behaviourist school of thought. One can invoke the existence of nervous or psychic energy which is discharged according to the mechanical law of least resistance. Which action is performed is a matter of which channel is followed by the nervous energy that governs one's organic and bodily processes. Opting for one response over another is thus explained as the 'switching of the liberated nervous energy on to another line' (STE 18, 19, 21). Alternatively one can appeal to the activity of biologically grounded reflexes. When the sophisticated patterns of behaviour developed in our adult life fail to meet the demands generated by threatening or otherwise troublesome situations, we automatically revert to a response set off by the nerve circuit that conditioned our reactions at the early stages of our development. Locating the source of emotion in the 'primitive circuit' of reflex behaviour operative in very early childhood, allows the 'pure behaviourist' to conceive of emotions as basic and universally valid modes of adaptation (STE 20). Contemporary neurobiological theories provide elaborate versions of this approach that identify basic emotions with a small set of reflex mechanisms. However the details of the relevant mechanism are filled out, the main point is that emotion constitutes a fall-back option for an organism when 'all the ways are barred' and the going gets tough (STE 39).

The plausibility of this account can be challenged in a number of ways some of which are less effective than others. Sartre, for one, avoids a wholesale attack on behaviourism, arguing instead that as a theory it fails to deliver on its promise of restoring the reality of emotional phenomena by looking beyond the narrow confines of bodily perturbations at the meaning of our transactions with the world. For those transactions to be meaningful two criteria should be met. The first is that the emotional transaction should be an adaptation of the organism to the situation. If this condition is to be met, then the organism should be aware of the behaviour conducive to the declared goal, the difficulties involved in behaving 
that way, the availability of adopting an alternative behaviour, and the opting for that alternative as (in a sense a sub-optimal, but nevertheless, functional) way out of an impasse. Hence, the occurrence of the alternative behaviour should be something other than a mechanical process of switching nervous energy channels. Thus, the second criterion is that the account should not leave behaviour proper out of its picture. Nervous energy discharged at random is not just sub-optimal behaviour: it is no behaviour at all. Analysing emotive behaviour as a set of arbitrary organic diffusions 'would be less like a behaviour of defeat than a lack of behaviour' (STE 19).

Sartre's main argument against behaviourism is that it fails on its own terms. Note, though, that an analogous problem is faced by the functionalist account, propounded by Gestalt Psychology - and partly endorsed by Sartre (STE 27). Emotional reaction is here interpreted as an abrupt solution to a problem, whereby the prescribed form of behaviour is substituted by behaviour that cancels the demands made on the subject through changing the shape of his or her situation. However, the mere affirmation of the occurrence of a form of behaviour does not amount to an explanation of that occurrence. If the explanation to be sought in the end is brought about by the occurrence, then an account is owed of how and why a particular end calls for, and brings forth, a particular form of behaviour. What we are offered, instead, is the description of the break up of one form of behaviour followed by the reconstitution of another form of behaviour. The result is an account of a succession of forms that sounds true but incomprehensible. The missing ingredient, according to Sartre, is an explication of the meaning of the forms that, according to Gestalt theorists, constitute an emotion.

Behaviourism fails to interpret emotion as a meaningful aspect of our being in the world. Emotion is meaningful because it is a conscious adaptation of the agent to his or her situation. The exact nature of adaptation involved in an emotional episode will be discussed in the next, and final, section of this chapter. We should stress, though, that the discussion that follows grants Sartre an important assumption: that it is not possible for emotions to acquire their significance through a process from which consciousness is absent. Sartre, in other words, rejects the belief in the reality of unconscious emotion. Talk of the unconscious, in the context of the Sartrean exploration of emotions, refers mainly to two things. It can denote an emotion whose existence is not in any way present to consciousness. Or, it can refer to emotional phenomena whose meaning lies in the unconscious. It is the latter issue that occupies Sartre in the Sketch for a Theory of the Emotions. Although his philosophy is inhospitable to unconscious states in general, it is important not to mistake his critique of the psychoanalytic view of emotions for a simplistic affirmation of the alleged omniscience of self-consciousness. In particular, the signification of a conscious event need not be explicit: 'there are many possible degrees of condensation and of clarity' (STE 41). Sartre's refusal to appeal to unconscious causes in interpreting emotional experience is based on the 
methodological credo that 'we should not interrogate consciousness from outside, but from within: that we should look into it for its signification' (STE 42). Elsewhere we have offered a reconstruction and qualified defence of the rejection of unconscious emotional states. ${ }^{23}$ Here we shall focus on Sartre's positive account of how affective awareness relates to emotional action.

\subsection{SARTRE on EMotional ACtion}

A common way of presenting Sartre's view is with the catch phrase: 'emotions are actions'. That claim expresses the metaphysical thesis that emotion itself is a type of event that falls under the category of action. However, a careful reading of Sartre's text indicates that the catch phrase is misleading. The core of the Sartrean view is that during an emotional episode one's relation to the world is 'magically' transformed by means of one's body (STE 39-41). Let me explicate what this claim means.

The world is understood as a totality of phenomena linked by a complex network of references to each other. The way in which each phenomenon relates to others defines the type of world encountered by the subject. In the world of daily activity we experience reality as a combination of demands (for projects awaiting completion, bills to be paid, walls to be decorated) and affordances (given by fast computers, bank transfers, or D.I.Y. shops). The link between demands and affordances is itself experienced as ruled by deterministic processes between causes and effects. The 'instrumental world' of action is captured in the 'pragmatic intuition' of the situation that makes certain moves available for the subject, while denying him or her others (STE 39). And this relates to a crucial contrast between action and emotion: for Sartre, the world encountered in emotional experience - what we variously characterize as a 'hateful', 'joyful', or 'bleak' world far from being identical to the world of action is clearly distinguished from the instrumental world (STE 35). The distinction is twofold. On the one hand, the 'emotional apprehension' of the world hooks on to those qualities or aspects that carry affective meaning for the agent, while the 'pragmatic intuition' focuses on features of the situation that make or not possible the execution of a task, the realization of an objective, or the creation of a product. On the other hand, the agent's response in an emotional episode engages the overall stance and physiology of the body not so as to effect material changes in the world but so as to alter his or her perception of reality, and, through that, his or her relation to the world: 'during

23 'The Case Against Unconscious Emotions' Analysis, 67 (2007): 292-9. 
emotion, it is the body which, directed by the consciousness, changes its relationship to the world so that the world should change its qualities' (STE 41). That change in qualities is called by Sartre 'magical' (STE 40, 43, 59). What makes the transformation of the word magical is precisely that what changes is not the material constitution of reality but how reality appears to the agent and, consequently, how the agent will respond to a thus transformed reality.

The notion of 'emotional response' is rather ambiguous, so a few clarifying remarks are in order. The analysis propounded by Sartre highlights the functional character of emotional response, not only in the case of 'active emotions' (as when one's shouting reduces the chances of properly listening to what the other person says) but also in the case of 'passive' emotions (as when one's bowed head and bent posture limits the range of one's vision so that as little as possible of the cruel world is taken in). There is, though, a notion of 'emotional response' that attaches to action which, while it can be described independently of the occurrence of emotion, is thought to be somehow better accounted for by reference to the emotion preceding the particular action.

Let us distinguish among the following scenarios regarding one's running away from a dangerous-looking bear. Case One is where the agent weighs his or her options, and after relevant deliberation, decides to create quickly a sufficient distance between him- or herself and the bear. Case Two is as in the previous scenario, but with the emotion of fear preceding the thought and action process described in Case One. Case Two can be subdivided into Case Two (a), whereby the fear experienced and the resulting action are temporally successive but otherwise unconnected; and Case Two (b), whereby the fear causes the deliberating process that results in the relevant action. In Case One, the running away is rationalized by reference to the thought process (usually taken to include the putting together of one's beliefs and desires) that aims to lead the agent out of danger. In Case Two (b), the running away is accounted for (at the level of explanation) and also rationalized (at the level of justification) by invoking the emotion of fear, because it is that emotion that initiates the relevant thought and action processes. However, none of the above Cases satisfies Sartre's description of fleeing as an emotional response.

Case One is a non-starter in the present context because, on the one hand, it includes no reference to emotion, and, on the other hand, it implies an analysis (in terms of reflective consideration and manipulation of one's own beliefs and desires) that is false to the phenomenology of normal human activity (which, according to Sartre, is a non-reflective, outward-looking engagement with the objects, tools, and tasks of a situation).$^{24}$

Case Two (b) offers a more interesting and arguably correct account of the phenomena involved. What it presents, though, is not an analysis of emotional

${ }^{24}$ An intentionalist view consistently discussed and defended by Sartre; see esp. STE 36-8, BN III, 2, i. 
response but of prudential action - and the two types of event are markedly different. Running out of prudence is acting according to a plan; emotional fleeing, on the other hand, is a 'magical behaviour which negates the dangerous object with one's whole body, by reversing the vectorial structure of the space we live in and suddenly creating a potential direction on the other side' (STE 43). It is not a case of reaching for shelter (as in prudential behaviour) but of 'forgetting' or 'negating' the threat. The dangerous object is the focal point of fear, and - contrary to the case of prudential action - the faster one runs (the louder one shouts, the further one withdraws) the more afraid (or angry, or sad) one feels.

The Sartrean analysis of emotion ranges over a wide variety of phenomena that could not be reviewed in the present chapter - not least because several of his points are simply acute observations made in the course of his unique narration of human phenomena, for which there is no substitute other than reading Sartre's text itself. I would like to conclude the discussion by drawing attention to some parts of the text that highlight the Sartrean approach to affective phenomena.

First, behaviour on its own (including one's overall conduct or particular actions $v i s \grave{a} v i s$ a situation) forms an important and integral part of emotional phenomena but is not, and should not be conceived as, exhaustive of what an emotion really is: 'behaviour pure and simple is not emotion, any more than is the pure and simple awareness of that behaviour' (STE 48). Secondly, emotional experience cannot be dissociated from the body on pain of 'falsity' of the professed emotion: 'the physiological phenomena ... represent the genuineness of the emotion, they are the phenomena of belief' (STE 50). Thirdly, what the agent believes is not some reflective statement about his or her own thoughts or bodily processes but the reality of the affective meanings that make up the object upon which the emotion feeds: 'Consciousness does not limit itself to the projection of affective meanings upon the world around it: it lives the new world it has thereby constituted - lives it directly, commits itself to it, and suffers from the qualities that the concomitant behaviour has outlined' (STE 51).

The active dimension of affective phenomena is important even in cases where ordinary discourse emphasizes passivity. Moods, especially those of a negative valence, are commonly thought of as passive states that are not directly related to the world outside the subject. We saw, in section 9.3, how Heidegger resisted that view by underlining the capacity of Stimmungen to disclose the very being of the world in general. For Sartre, the world's involvement in the constitution of moods is more specific, and, in that sense, more prominent. Consider tristesse passive, a mood that bears passivity on its sleeve. Passive sadness is characterized by paleness, muscular relaxation, and 'withdrawal', whereby one prefers solitude in small spaces to lecture halls and public squares: '..." To be alone", as they say, "with one's sorrow". But that is not true at all: it is good form, of course, to appear to meditate deeply over one's grief. But cases in which a sorrow is really cherished are rather rare' (STE 43). In most cases, Sartre maintains, passive sadness arises when one of 
the (e.g., material) conditions of my activity is no longer there, yet the demands placed by my situation are still here. I am therefore required to substitute that to which I am accustomed, with means new to me - and that is precisely what I cannot bear to do. Passive sadness, according to Sartre, is not the causal imprint of the world on my soul but my response to my predicament: 'my melancholy is a method of suppressing the obligation to look for [new means], by transforming the present structure of the world, replacing it with a totally undifferentiated structure' (STE 44). What distinguishes the emotive response from a practical response is that the desirable transformation is not effected by altering the shape of things but by altering myself, e.g., by 'dimming the lights' [mettre en veilleuse] of our daily life (STE 44).

I think that, despite the differences in their ontology, Sartre is in fundamental agreement with Heidegger on what sustains the phenomenological importance of emotional awareness. For Heidegger, affective experience enables the primordial apprehension of the concrete reality that is our being-in-the-world. Similarly, for Sartre, affective experience is neither blind nor self-referential: 'Emotion is a specific way of apprehending the world' (STE 35).

\section{Further Reading}

\section{General}

Cerbone, David (2006), Understanding Phenomenology (London: Acumen).

Mickunas, Algis (1997), 'Emotion' in Encyclopedia of Phenomenology, edited by Lester Embree et al. (Dordrecht: Kluwer Academic Publishers): 171-7.

Moran, Dermot (200o), Introduction to Phenomenology (London: Routledge).

Schroeder, William (2005), Continental Philosophy: A Critical Approach (Oxford: Blackwells).

Sokolowski, Robert (2000), Introduction to Phenomenology (Cambridge University Press).

\section{Heidegger}

Carman, Taylor (2003), Heidegger's Analytic (Cambridge University Press).

Dreyfus, H. and Wrathal, M. (eds.) (2004), A Companion to Heidegger (Oxford: Blackwell). uignon, ${ }^{\Phi}$ Harles (ed.) (2006), Cambridge Companion to Heidegger (Cambridge University Press).

Harr, M. (1992), 'Attunement and Thinking' in H. L. Dreyfus and H. Hall (eds.), Heidegger: A Critical Reader (Oxford: Blackwell).

Inwood, Michael (1999), A Heidegger Dictionary (Oxford: Blackwell). 
Mulhall, Stephen (1996), Routledge Philosophy Guidebook to Heidegger and Being and Time (London: Routledge).

Ratcliffe, Matthew (2002), 'Heidegger's Attunement and the Neuropsychology of Emotion' Phenomenology and the Cognitive Sciences 1: 287-312.

Staehler, Tanja (2007), 'How is a Phenomenology of Fundamental Moods Possible?' International Journal of Philosophical Studies Vol. 15(3), 415-43.

\section{Sartre}

Barnes, Hazel (1967), An Existentialist Ethics (Alfred A. Knopf).

Hatzimoysis, Anthony (2009), The Philosophy of Sartre (London: Acumen).

Howells, Christina (ed.) (1992), Cambridge Companion to Sartre (Cambridge University Press).

McBride, William Leon (ed.) (1996), Sartre and Existentialism: Philosophy, Politics, Ethics, the Psyche, Literature, and Aesthetics, 8 Vols. (London: Routledge).

McCulloch, Gregory (1994), Using Sartre (London: Routledge).

Murphy, Julien S. (ed.) (1999), Feminist Interpretations of Jean-Paul Sartre (Pennsylvania State University Press).

Priest, Stephen (200o), The Subject in Question (London: Routledge).

Solomon, Robert C. (2001), Phenomenology and Existentialism (Rowman \& Littlefield).

Wider, KathleEn (1997), The Bodily Nature of Consciousness (Ithaca, N.Y.: Cornell University Press). 
Peter Goldie $\quad$ 09-Peter Goldie-Chapter09 Page Proof page 236 29.5.2009 9:15pm 